\title{
TURISMO Y TERRITORIOS EN TRANSFORMACIÓN EN COMUNIDADES MAPUCHE DEL SUR DE LA PROVINCIA DEL NEUQUÉN, ARGENTINA
} Tourism and Territories in Transformation in Mapuche Communities of the Southwest of Neuquén Province, Argentina

\section{MARCELO IMPEMBA* \& MARÍA GRACIELA MARAGLIANO**}

Fecha de recepción: 23 de mayo de 2019 - Fecha de aprobación: 13 de agosto de 2019

\section{Resumen}

Los temas expresados en el presente trabajo son el resultado de diferentes proyectos de investigación y extensión universitaria que han abordado el desarrollo turístico y su incidencia sociocultural y económica en comunidades mapuche de la región andino-patagónica del sudoeste de la provincia argentina del Neuquén. Abordar el turismo contextualizado espacial e históricamente en relación con comunidades indígenas representa un amplio campo de investigación sobre los cambios en sus condiciones ambientales, territoriales y prácticas productivas. Entre los ejes que han guiado el trabajo de campo se pueden destacar el estudio de sus acciones reivindicativas y de las representaciones y estigmatizaciones del resto de la sociedad desde la perspectiva del campo turístico.

Palabras clave: comunidades mapuche; territorio; desarrollo turístico.

\section{Abstract}

The topics expressed in this work are the result of different research and university extension projects that have addressed tourism development and its socio-cultural and economic impact on Mapuche communities in the Andean-Patagonian region of the southwest of the Argentine province of Neuquén. Addressing spatially and historically contextualized tourism in relation to indigenous communities represents a broad field of research on those changes in their environmental and territorial conditions and their productive practices. Among the axes that have guided the fieldwork we can highlight the study of their vindicative actions and of the representations and stigmatizations of the rest of society from the perspective of the tourist field.

Keywords: mapuche communities; territory; tourist development.

\footnotetext{
"Dr. en Ciencias Antropológicas. Investigador, Facultad de Turismo, Universidad Nacional del Comahue, San Martín de Los Andes, Neuquén, Argentina. Correo-e: impemba@smandes.com.ar " Especialista en Turismo Sustentable. Investigadora, Facultad de Turismo, Universidad Nacional del Comahue, San Martín de Los Andes, Neuquén, Argentina. Correo-e: maragliano@smandes.com.ar
} 


\section{Transformaciones y reivindicaciones en contextos turísticos}

En el marco del avance de las políticas públicas neoliberales en Latinoamérica y, en los últimos tres años, en la Argentina, se ha venido consolidando un sostenido proceso de ajuste y recesión, una regresión en las conquistas sociales, la implementación de un discurso dominante y globalizado y la instauración de formas represivas contemporáneas sobre sectores sociales vulnerables ante una conflictividad creciente.

El turismo, como actividad económica, ha provocado un gran interés por parte de diversos sectores -público y privado- en cuanto fuente generadora de ingresos y empleos, con ventajas comparativas a corto y mediano plazo que favorecerían su desarrollo tanto a nivel local como regional o nacional. Los países de América Latina -como en nuestro casocategorizados de "emergentes"1 posicionan el turismo en especial como uno factor que posibilita mejorar los cada vez mayores índices de desempleo y pobreza. Este rubro es considerado como una estrategia para paliar las situaciones de crisis de las actividades productivas tradicionales y regionales.

Esta forma de entender el turismo se ha consolidado en los últimos cincuenta años en diversos ámbitos académicos. En muchos de ellos se concibe esta actividad como una "industria sin chimeneas" y una fuente generadora de divisas. Esta visión omite un análisis crítico más amplio e integral y un debate sobre el modelo de desarrollo turístico implementado en las más diversas realidades que permita comprender y considerar las necesidades y los impactos en las poblaciones locales o receptoras.
Los espacios rurales norpatagónicos han sido escenarios de transformaciones vinculadas a actividades extractivistas, turísticas y de desarrollo inmobiliario que reflejan una creciente concentración productiva acompañada por la apropiación de territorios. Las consecuencias son territorios fragmentados y en disputa con la población indígena y campesina, lo que redefine las configuraciones identitarias, expresadas por las tensiones en el uso y el acceso a la tierra (Impemba, 2005).

Dichas transformaciones están mediadas por relaciones interétnicas, donde el turismo es una manifestación socioeconómica reciente en un territorio en conflicto. La inserción de la actividad turística en territorios rurales indígenas permite visibilizar la complejidad y la heterogeneidad de esta trama, misma que nos hemos dedicado a estudiar y analizar críticamente en las últimas dos décadas. Esta está conformada por las diferentes formas que adoptan las estrategias de intercambio y la construcción social de las relaciones interétnicas -en particular en las comunidades mapuche- en contextos mediatizados por el campo turístico de esta región patagónica, específicamente en el caso del sudoeste de la provincia del Neuquén, donde se extiende, de norte a sur, el denominado Corredor de Los Lagos².

Diversos proyectos de investigación, de desarrollo tecnológico y social (PDTS) y de extensión y voluntariado universitario nos han permitido abordar dimensiones de análisis entre ellas, los procesos de reterritorialización y de transformaciones sociales- que se inscriben en el estudio de las poblaciones mapuche en esta región en relación con sectores estatales dominantes. En el caso de la Administración de Parques Nacionales, ha prevalecido, desde 
su creación, el no reconocimiento o integración hasta llegar, por ejemplo, en el caso de los parques nacionales Lanín y Nahuel Huapi, a una política de co-manejo, con sus diversos vaivenes entre avances y retrocesos. La relación entre el Estado (nacional, provincial y/o municipal) y las comunidades mapuche sobre el manejo, la administración, la promoción y la comercialización de actividades y productos turísticos merece un abordaje particularizado, en el que se incluya su reposicionamiento étnico.

En el eje de una visión antropológica del turismo, este trabajo se contextualiza espacial e históricamente en relación con comunidades minoritarias y con un fenómeno social de múltiples implicancias entre los actores sociales que participan en él. Al poner en juego modelos de desarrollo impuestos, el turismo representa una extensión de las relaciones de subordinación y sometimiento desde factores de poder tanto públicos como privados, o ambos en forma vinculante. Su abordaje requiere caracterizar y exponer los procesos históricos y sociales que dieron forma a las comunidades mapuche y poder así vincular, conocer y profundizar en las problemáticas preexistentes y las acciones reivindicativas. El punto de partida aspira, en definitiva, a indagar en las complejas interrelaciones que se generan a partir de las prácticas turísticas, que en general reproducen las representaciones y las estigmatizaciones del resto de la sociedad prevalecientes durante el siglo XX.

Los modelos de desarrollo implementados en estos territorios son elaborados desde los entes oficiales intervinientes. Por la falta de alternativas, el crecimiento poblacional en las comunidades y las manifestaciones de una interculturalidad incompleta, las poblaciones indígenas recrean un imaginario acerca del turismo desde la idea de progreso económico. Desconocen, en muchos de los casos -tal vez la gran mayoría-, las dimensiones "ocultas" en el discurso político y hegemónico, como son las implicaciones sociales y culturales que condicionan las prácticas cotidianas de las poblaciones involucradas directa e indirectamente en emprendimientos de este tipo, que inciden en las estructuras y las organizaciones comunitarias, domésticas y/o familiares.

Luego de que sufrieran una histórica invisibilización en el plano social y político, en la actualidad se ha presentado y profundizado cierta contradicción respecto de las comunidades mapuche: por un lado, la existencia de un fuerte rechazo a sus reivindicaciones étnicas y especialmente territoriales, mientras que, por el otro, se incorpora lo étnico como parte de los productos turísticos que le otorgan "carácter" y "originalidad" a esta actividad en la región patagónica. Vemos, efectivamente, que las formas institucionalizadas incorporadas en los diferentes procesos de desarrollo turístico, primero con la creación de Parques Nacionales y luego con la provincialización de Neuquén, han tenido como consecuencia la apropiación de la cultura y el patrimonio como recurso turístico en localidades patagónicas que en su mayoría se han caracterizado por el ocultamiento, o directamente la negación, de la existencia de sus poblaciones indígenas, siendo los casos más emblemáticos San Martín de los Andes y Villa La Angostura.

El paradigma que ha prevalecido y se ha sostenido desde muchos ámbitos (políticos y/o académicos) plantea el turismo como una fuente generadora de riquezas, que se desentiende de las necesidades o las identidades de las comunidades locales o receptoras, poniendo el énfasis 
en las ganancias económicas por encima de las identificaciones regionales. Este enfoque reduccionista del turismo lleva a la masificación y el debilitamiento, e incluso a la pérdida, de los patrimonios locales y a la homogeneización de la cultura o su folclorización. El patrimonio, ya sea cultural o natural, pasa a ser un objeto de interés comercial, un objeto de consumo que relega los valores simbólicos y significativos que le atribuyen los grupos sociales locales y a partir de los cuales se constituyen y adquieren identidad.

Las consecuencias generadas por esta actividad socioeconómica en poblaciones originarias sigue representando, a pesar de todos los esfuerzos emprendidos por diferentes grupos de investigación, un amplio campo para el abordaje de las condiciones ambientales y territoriales sobre las que se implanta. También se debe ahondar en los cambios producidos por el proceso de expansión turística en las prácticas productivas y las estructuras organizacionales, y su incorporación e imposición al interior de las unidades domésticas y/o comunitarias. No podemos obviar el resultado de estas prácticas recreadas y sostenidas desde un capitalismo tardío en contextos rurales y étnicos e implantadas en una realidad basada, históricamente, en una economía de subsistencia.

El turismo no remite exclusivamente a un espacio físico donde se desenvuelven actividades relacionadas con este o donde solo se prestan servicios turísticos. Las políticas públicas impuestas gracias a factores hegemónicos del Estado en conjunción con sectores privados y basadas en la subordinación y la explotación de los recursos, esperan que los pobladores elegidos o con iniciativa se conviertan en pequeños empresarios exitosos, bajo la lógica del emprendedurismo como una herramienta de desarrollo principalmente económico. De esta manera, se consolidaría la apertura de las poblaciones indígenas a la modernidad y el capital, lo que promovería su diversificación económica, su bienestar y mejores condiciones de vida. Sin embargo, no se toman en cuenta las consecuencias que tiene y que ha tenido este modelo de turismo sobre poblaciones empobrecidas.

Contradictoriamente, el turismo ha sido un factor que ha favorecido la visibilización de las poblaciones indígenas. Ha colaborado, sin proponérselo, al reposicionamiento de las propias comunidades mapuche -en el marco del lento pero consolidado proceso de reivindicación étnica y de reclamos territoriales-. Es por ello que en el siglo XXI se plantean nuevas claves para la relación entre cultura, patrimonio y turismo que superen las perspectivas tradicionales de confrontación: cultura frente a economía o turismo frente a patrimonio.

\section{La estatalidad sobre territorios étnicos y turísticos}

El turismo es un fenómeno social de múltiples implicancias socioeconómicas, políticas, ambientales y culturales. El análisis crítico de las variables y las condiciones estructurales en las que se desenvuelve y de sus consecuencias en poblaciones indígenas representa una oportunidad y un desafío para abordar y exponer aquellos cambios que acarrea en las condiciones ambientales, territoriales, prácticas productivas y sociales de las comunidades minoritarias y rurales en las que se incorpora. 
Desde la denominada Campaña del Desierto ${ }^{3}$ y hasta la actualidad se ha configurado un espacio social complejo en toda la Patagonia argentina, tanto de intercambio como de sometimiento y/o sobrevivencia. Como sostiene Laura Kropff (2005), la apropiación y la distribución de los territorios patagónicos por parte del Estado nacional -luego de las sucesivas campañas militares a fines del siglo XIX-, que continuaron ya entrado el siglo $\mathrm{XX}$ por parte de Parques Nacionales ${ }^{4}$, tuvieron el fin de consolidar la "estatalidad" en áreas de frontera. A las poblaciones mapuche que habitaban ahí con anterioridad a la llegada del Ejército, los parques y los colonos/inmigrantes, se les asignaron los territorios sobrantes o marginales para el desarrollo de sus actividades productivas de subsistencia.

El Estado nacional, a través de la Dirección de Parques Nacionales en la década de 1930 -denominada luego Administración de Parques Nacionales-, promovió y ejecutó una política territorial en la que el turismo regional y selectivo, destinado a sectores de poder nacionales y extranjeros, fue uno los ejes de desarrollo de toda esta región del sur argentino. Con base en el imaginario de "la Suiza argentina", como infiere Maragliano (2010), a partir de la idealización y la construcción de esa imagen se elaboró un programa atractivo para las clases dominantes, los turistas internacionales o los inversores de la "élite" porteña, para que se sintieran vacacionando en Europa. De acuerdo con esa dirección ideológica se requirió, para conseguir ese objetivo, producir un "lugar" elaborando una arquitectura que rememorara a la del hemisferio norte.

Como todas las poblaciones indígenas (y no indígenas) que quedaron bajo jurisdicción de Parques Nacionales, en el caso estudiado estas fueron incorporadas al territorio bajo la categoría creada por esta institución, la de "pobladores" o más técnicamente P.P.O.P. ${ }^{5}$. Esta condición los restringía a una situación de precarización ocupacional sobre un sector o fracción de tierra, con fuertes restricciones para el manejo de su ganadería o para realizar mejoras en sus parcelas. Los pobladores mapuche sufrieron una política de "invisibilización", o directamente de negación, por parte de los estamentos estatales y de las sociedades de frontera, a pesar de formar parte de la cotidianeidad de los diferentes centros urbanos, de su aporte e implicancia en la construcción de una nacionalidad que se estaba consolidando.

En la segunda mitad del siglo $X X$, con posterioridad a la provincialización del Territorio Nacional de Neuquén en 1958 y en especial a partir de la década de 1970, la intervención del Estado neuquino se hizo más sostenida sobre toda la región sur. Ahí se determinó que el eje de su desarrollo iba a ser el turismo y en ese sentido se implementaron políticas públicas de promoción turística de base e impronta desarrollista, con importantes obras de infraestructura. La herramienta que brindaba la planificación estatal estaba destinada a consolidar esta actividad como economía de enclave en toda la región.

En consecuencia, los espacios territoriales anteriormente concebidos como improductivos y asignados a los pobladores mapuche comenzaron a tener un alto valor paisajístico y, por lo tanto, turístico-inmobiliario. Al convertir la naturaleza y el paisaje con sus habitantes en atractivos turísticos y, por lo tanto, en recursos económicos, las áreas donde habitaban comunidades mapuche ya conformadas y en algunos casos reconocidas se volvieron necesarias para llevar 
a cabo las actividades turísticas. Las relaciones con estos espacios, que durante décadas se habían acotado a aspectos específicos vinculados a la producción, la gestión pública y la distribución de recursos (agropecuarios, forestales, de abastecimiento), adquieren una nueva forma. Las construcciones de las relaciones interétnicas comenzaron a estar mediatizadas por el campo turístico.

La compleja situación antes descripta se acentúa bajo las condiciones de dependencia a las que estaban sometidas las poblaciones más vulnerables, que ceden a la subordinación generada desde el Estado. En el caso particular de Neuquén, desde su provincialización a fines de los años cincuenta, se reprodujo un modelo basado en el usufructo de las rentas petrolífera y gasífera. En relación con los grupos familiares de pequeños productores se aplicó una política más asistencialista que productivista -en oposición al desarrollo agroganadero y la promoción de pequeñas unidades productivas autogestionarias-. La decisión política de incorporar al turismo como otra actividad económica implica para el Estado neuquino la misión de diversificar la matriz productiva provincial, dependiente de la explotación de hidrocarburos.

El discurso oficial de la provincia del Neuquén -que en su Constitución Provincial reconoce la preexistencia del poblamiento mapuche en su territorio- ha reproducido, desde el inicio de su vida institucional, los preceptos de reconocimiento, respeto, integración y diversidad de la población indígena. Desde esa posición, se ha valido de elementos aislados y seccionados de "lo mapuche" (simbología, nombres, mitos y leyendas) para la construcción de su estatalidad. En el marco de los efectos promocionales del turismo provincial, su incorpo- ración le ha servido para otorgarle los rasgos nativos y exóticos necesarios que condimenten étnicamente los diversos productos turísticos ofrecidos: "Neuquén (en voz mapuche 'audaz, pujante') tiene raíces culturales de la tradición milenaria mapuche (mapu - tierra, che - gente). Esta tradición se refleja en cada una de las manifestaciones de la vida cotidiana de estas comunidades" (NEUQUENTur, 2016) ${ }^{6}$.

Sin embargo, a pesar de esta puesta en valor, en las relaciones interétnicas que cruzan la vida social y política de la provincia se sostienen los mismos enfoques que definieron las identidades y las alteridades de los grupos indígenas en el último siglo: prevalece lo homogéneo sobre lo diverso y se integra lo indígena-nativo-mapuche bajo una concepción basada en el sometimiento. La dirigencia neuquina de los últimos sesenta años, es decir, desde la provincialización, es pionera en un modelo de pluralismo basado en una subordinación tolerante que, aun dándole cierta cabida a la heterogeneidad, no cuestiona el primado de tendencias homogeneizadoras (Williams, 1993).

Así, el ingreso al campo turístico de las comunidades mapuche afines al ejecutivo provincial ha sido promovido, e incluso impuesto, como política estatal. Esta situación ha generado en las propias comunidades, y en particular en sus cuadros dirigenciales, dudas e inquietudes respecto de lo que ellos consideran un avance del turismo dentro de sus territorios. Si bien le reconocen un factor que refuerza y sostiene la reivindicación territorial, también lo colocan en un lugar de interrogante en cuanto a los impactos que pueda generar al interior de las comunidades este salto a la modernidad que representa el turismo. "El turismo debe tener una interrelación directa 
con la conservación y utilización sostenible de la diversidad biológica. El turismo es sostenible si es controlado por los Lof" (Confederación Mapuce de Neuquén, 2010, p. 82).

En cierta medida se ha reproducido en estos ámbitos el posicionamiento que ha predominado como consecuencia de la masificación del turismo basado en el mercado y anclado en el esquema propuesto por el desarrollismo en cuanto a generar una economía de enclave especializada -en este caso en el turismo-. Esta orientación ideológica y metodológica reproduce todos los esquemas de concentración del poder y de la distribución de los ingresos, basándose en la escenificación de las virtudes naturales o culturales. De ahí que las características del turismo desarrollado y, por ende, del turista que demanda sus servicios, haya influido en el tipo de inversiones o las distintas formas que adopta el capital en cuanto a la apropiación de servicios por los prestadores.

A partir de su negación como integrantes de esta formación social de frontera, los pobladores de origen mapuche sufrieron la inserción en un sistema interétnico que los subordinó durante los últimos ciento veinte años. En la región del sudoeste neuquino, donde las diferentes instancias estatales crearon y recrearon una imagen bajo la impronta eurocéntrica de una región "alpina" de connotaciones centroeuropeas, la alteridad y las relaciones sociales con este colectivo humano se construyeron sobre la base de una homogeneización de grupo, sustentada en la subordinación y la dominación, tanto en sus aspectos comerciales, educativos y políticos como en su reproducción en el campo turístico (Radovich \& Balazote, 2000).

\section{La construcción social del patrimonio}

En el devenir de una región turística con una impronta europea, lo indígena comienza a formar parte de las excursiones como un elemento más del paisaje. Este aporta un toque exótico para "enriquecer" la oferta turística: elementos recortados de una cultura ignorada y negada por los integrantes de la propia superestructura turística. En la redefinición y construcción de la alteridad a partir y como consecuencia del posicionamiento como atractivo turístico, los atributos de la desconocida cosmovisión mapuche representan fragmentos que hacen referencia a una cultura del pasado, puesta en el mercado para ser consumida desde sus rasgos folclóricos y tradicionales (Balazote, 2006). Este recorte no incluye aspectos conflictivos, como las reivindicaciones culturales y territoriales que se han desarrollado en los últimos veinte años en la región. Con la apropiación de esta cultura y sus habitantes como recurso turístico, se ha incorporado paulatina y sostenidamente lo mapuche desde una posición ahistórica, descontextualizada y despojada de toda connotación social y política.

Como se destaca en este trabajo, ciertas políticas públicas tratan el turismo como factor y objeto de crecimiento, pensándolo como una actividad meramente económica. Desde esa óptica se implementan proyectos a corto plazo sin tener en cuenta que la actividad turística, si bien puede generar ingresos, se desarrolla en un espacio socioterritorial, con un patrimonio construido socialmente que representa simbólicamente la identidad local. Sin embargo, cada vez es mayor el interés en el mercado del patrimonio, tanto cultural como natural, erigido como un objeto de interés turístico y comercial. Este pasa a ser un componente privilegiado de 
la demanda de consumo cultural; un "objeto cultural de consumo" que relega el valor simbólico-significativo del patrimonio para la identidad y la integración de los grupos sociales. Autores como Prats (1997) señalan que las activaciones patrimoniales en la actualidad han adquirido dimensiones nuevas a partir del ocio y el turismo. Más allá de los significados identitarios, el patrimonio se evalúa como "recurso" y se valora como "factor de desarrollo", activado como artículo desde "su uso" a partir de las demandas de la sociedad de consumo.

Las comunidades mapuche aquí estudiadas no han escapado a esta forma de tratar el patrimonio que se mueve entre dos lógicas diferentes: por un lado, la lógica identitaria, la percepción del patrimonio desde los procesos de identificación social, y, por el otro, la lógica de mercado, la percepción del patrimonio desde la rentabilidad económica. La perspectiva desde la cual se visualiza la conservación, la protección y la difusión del patrimonio se basa en una utilidad social, en la que esta no es exclusivamente un rendimiento económico, sino una finalidad educacional, socializadora y comunicacional.

Pero el patrimonio ha sido redescubierto también como factor dinamizador de las economías locales, a veces bajo la dirección de las instituciones políticas y empresariales. En ese caso se trata del aprovechamiento que puede tener el patrimonio como recurso para el desarrollo de determinadas zonas, sobre todo en los contextos rurales donde se ha diversificado la mirada sobre sí mismo para encontrar alternativas a la cosmovisión urbana y la globalización lo suficientemente atractivas como para generar riqueza. Así, bienes que habían sido infrautilizados adquieren un nuevo valor: las artesanías, el paisaje, la gastronomía, la arquitectura tradicional, la fauna y la flora, las fiestas, entre otros.

Sin duda, el turismo constituye uno de los "activadores" del patrimonio en la actualidad. El sector turístico se ha transformado en los últimos años multiplicando su oferta y demanda. El incremento que ha tenido el patrimonio como objeto de interés turístico y comercial ha hecho que se constituya muchas veces en un componente privilegiado de las demandas de consumo cultural. En este sentido, Guerrero Valdebenito señala que "la activación patrimonial puede tener como motivación también una valoración económica [...] bienes que podrían ser intercambiados en un mercado, adquiriendo con ello la categoría de formas simbólicas mercantilizadas" (2005, p. 2).

El turismo no es solo un suceso económico, sino también una práctica social que no puede darse de la misma manera en todos los espacios. La actividad turística se inserta en un espacio previo, con tradiciones e identidades que muchas veces las políticas de planificación omiten. Se construye, así, una imagen que no posee ningún reflejo de los escenarios cotidianos. Como menciona Vera Rebollo: "El turismo es una práctica que se concreta en un espacio físico y social" (1997, p. 20), pero con frecuencia esta variable se minimiza bajo el predominio de la concepción del análisis económico. Rescatar que no es únicamente una actividad económica sino una práctica social es importante, ya que a la hora de analizar las políticas turísticas no se puede dejar de lado su componente social y cultural, además de las manifestaciones económicas que genera. De este modo, el turismo influye en todos los sectores de la vida cotidiana, en las creen- 
cias, en las concepciones de la identidad y en el espacio territorial.

La búsqueda del rendimiento económico que puedan aportar los elementos patrimoniales tiene, no obstante, sus riesgos y peligros, aun si su intencionalidad es perfectamente legítima. Los mayores problemas se plantean cuando se produce una disociación entre el valor económico y el valor simbólico, es decir, cuando se impone la lógica de mercado sin tener en cuenta las interpretaciones y las percepciones identitarias que pueda tener para individuos y colectivos sociales. Es entonces cuando el patrimonio puede transformarse en un producto. Sin embargo, el patrimonio es siempre patrimonio de alguien, aunque lo que es propio no siempre esté ratificado formalmente.

\section{Apropiación del turismo en las comunidades mapuche}

Al interior de las comunidades mapuche, el turismo aparece como una de las pocas alternativas productivas y fuente de ingresos posibles -si no la única- ante la escasez de oportunidades. La situación de pobreza estructural y las restricciones en cuanto a la disponibilidad y uso del espacio, con el consiguiente impacto de la actividad ganadera tradicional, sumado al aumento poblacional, han llevado a que muchas familias se incorporen al turismo con la expectativa de que les permita resolver sus condiciones de subsistencia. En otras palabras, ante la ausencia de opciones a la vista, el gobierno provincial, por un lado, y Parques Nacionales dentro de las áreas protegidas, por el otro, sostienen y promueven, desde lo discursivo, el turismo como una de las pocas salidas econó- mica y ambientalmente "sustentable". Esta política estaría solo destinada a pobladores con su grupo familiar, a modo de pequeños emprendedores situados en los márgenes de un sistema turístico fuertemente condicionado y capitalizado, para participar en los bordes de la turistificación de su espacio social.

La incorporación del turismo al interior de las comunidades mapuche en la región analizada, si bien representa una nueva alternativa económica para algunos de sus pobladores, se produjo sin planificación, de manera espontánea, como consecuencia del ingreso y el avance inevitable de una expansión turística que las alcanzó e incluso avasalló. Se impuso en los hechos una realidad que no las incluyó desde lo comunitario, pero sí como parte de un paisaje que se fue agregando a los diferentes productos turísticos, en especial en las poblaciones que se encuentran próximas a los destinos turísticos de la región andino-patagónica y/o en jurisdicción de Parques Nacionales.

Este paulatino, pero sostenido, aumento de turistas y de empresas turísticas que avanzaron sobre los territorios habitados por poblaciones indígenas, se fue complementando con cambios sociales a favor de los vientos democráticos de la diversidad. A inicios del actual siglo XXI, a la diversificación de la oferta turística bajo los formatos del turismo cultural-étnico-activación patrimonial se fue integrando, lenta pero continuamente, a los pobladores mapuche a la prestación de servicios turísticos a través de la inversión individual o comunitaria en pequeños emprendimientos productivos, referidos a la venta de comidas y artesanías, camping y guiadas a pie o a caballo (Impemba \& Maragliano, 2007). 
Entre las comunidades se dieron sustanciales diferencias en cuanto a la importancia que adquiere el turismo como fuente de ingresos en función de las especificidades de las áreas en que se asientan (áreas protegidas o provinciales, próximas a atractivos como costas de lagos u otros) por su ubicación con respecto a los centros turísticos o por las actividades que ofrecen. Sin embargo, el etnodesarrollo turístico, como sostiene Bonfil Batalla (1995), dista de ser una posibilidad, pues por el momento es sobre todo un constructo heterogéneo en sus formatos $y$, en consecuencia, su relevancia, incidencia y efectos es disímil.

Pero, en todos los casos, los pobladores debieron adecuar su vida cotidiana y organizativa familiar y/o comunitaria para prepararse y recibir a los turistas, tratando de adaptar sus condiciones de existencia a estas nuevas prácticas para ellos desconocidas. En algunos casos contaron con una capacitación básica, provista por entes gubernamentales y/o universitarios. Todas las experiencias coinciden en que las diversas prácticas turísticas y el mayor flujo de visitantes ocurren durante el período con el mayor volumen de trabajo de cada unidad doméstica, la temporada estival. Estos cambios no solo se manifiestan en las rutinas cotidianas de las familias, sino también en aquellos aspectos organizacionales internos, con impactos en las comisiones directivas que rigen los destinos políticos y administrativos de las propias comunidades.

A causa de esta nueva situación han comenzado a aparecer complejos problemas que derivan de la apropiación del espacio y la distribución de los ingresos generados a través y como consecuencia del turismo. Algunos de los enfrentamientos que ya se han planteado al interior de las comunidades son entre las familias que intervienen y las que no en la producción turística y la atención a los visitantes, con la aprobación de la comisión directiva respectiva. En este sentido, se plantea una cuestión inquietante para los pobladores mapuche: el avance-cuasi privatizador-sobre un espacio comunitario. La disyuntiva es si los recursos generados por el turismo deben aportar al bienestar de la comunidad toda distribuyéndose en forma equitativa o porcentual, ya que en definitiva se estaría aprovechando el territorio comunitario, un usufructo sobre algo que es propiedad de todos:

El capitalismo, en su fase expansiva, transforma instituciones económicas que originalmente se orientaban predominantemente a la satisfacción de necesidades familiares, y que Marx denominó economías de reproducción simple. El desarrollo capitalista expande una lógica de reproducción ampliada (Bedoya Garland, 2000 , p. 146).

Varios autores de la antropología económica han analizado la subordinación de las formas domésticas de producción, la supeditación del trabajo a la dinámica del capital y su proceso de transición a partir de unidades domésticas cuyo modo de producción correspondía a unidades precapitalistas, así como la resignificación de las relaciones de poder al interior de las mismas (Trinchero \& Balazote, 2007).

Como sostienen Sebastián Valverde y Eugenia Morey (2005) en relación con la dinámica de la producción de artesanías en el ámbito doméstico, la incorporación del turismo no puede atribuirse exclusivamente a factores endógenos de las propias unidades domésticas. Por el contrario, deben ser consideradas las condiciones estructurales que modifican y redefinen 
la dinámica económica de los grupos domésticos que integran las comunidades mapuche.

En el caso del turismo, este es un factor reciente en el devenir social y económico de las comunidades mapuche con consecuencias directas e indirectas del proceso de capitalización todavía a analizar. La cuestión planteada es si debe haber restricciones sobre el espacio que sea explotado turísticamente en el territorio de las comunidades y una suerte de coparticipación de los ingresos con el resto de los integrantes del paraje o comunidad, en la forma de un porcentaje o aporte, debido al aprovechamiento turístico y, por lo tanto, económico del territorio comunitario. En otras palabras, se cuestiona el uso turístico y el consiguiente impacto ambiental y social sobre una propiedad compartida.

Pero si solo se trata de adaptar las mismas lógicas de mercado y de pequeños emprendedores, el turismo que prevalecerá en este ámbito será el que, por un lado y en forma directa, favorezca el aumento del volumen de las transacciones turísticas en forma competitiva e individual para contribuir al mejoramiento en la calidad de vida de aquellos pobladores que participen directamente en él. Sin embargo, de acuerdo con el crecimiento en los niveles de pobreza y desempleo, en realidad solo minimiza el proceso de pauperización de los sectores subalternos registrado en los últimos años .

Ante esta compleja situación, el turismo comienza a vislumbrarse como un factor que suma nuevos componentes de conflictividad para los integrantes de las comunidades y/o que revitaliza los ya existentes. En cierta medida, al introducir un instrumento de la modernidad, como es el turismo, que reproduce formas de explotación de mercado, se favorece una suerte de privatización de una porción del suelo por parte de una familia o de grupo de pobladores, lo que genera una distinción respecto del resto de los integrantes de la comunidad desde un punto de vista social y económico.

En efecto, se han producido casos de asociación con capitales privados de familias o comisiones directivas para el desarrollo de "empresas" turísticas que van desde rentals de equipo de esquí en el Cerro Chapelco hasta la construcción y la gestión de pequeñas cabañas en parcelas familiares. No cabe duda de que aquí entra en juego el capital político y económico de los participantes en la construcción de las relaciones de poder intracomunitarias, en especial de aquellos que se apropian para su explotación de una fracción de territorio y de la consiguiente renta turística.

\section{A modo de cierre: \\ la visibilidad social del turismo}

Ante las condiciones hasta aquí expuestas, la visibilidad o la invisibilidad de la población mapuche mediatizada por el campo turístico depende de las dimensiones y las características de la disputa económica y simbólica en juego (Impemba, 2012). Por ejemplo, cuando se habla de poner en valor, en este caso un producto turístico étnico ${ }^{7}$, el intento es convertirlo en un recurso económico para su puesta en el mercado. "Esto suele exigir, por lo menos, la conservación de estos elementos, y facilita, por otra parte, al poder político, una vía rápida y segura para la actuación consensuada. La activación, más que con la puesta en valor, tiene que ver con los discursos" (Prats, 2005, p. 3). Lo cultural queda definido por su valor monetario, lo que lleva a adaptar dicho producto al gusto y necesidades del turista, 
quien determina, en definitiva, las formas de exponerse de un colectivo heterogéneo denominado comunidad mapuche.

En un contexto de mayor aceptación de la diferencia y la diversidad de género, sexual, religiosa y étnica, las comunidades indígenas -en nuestro caso el pueblo mapuche- han obtenido una mayor presencia y reconocimiento en lo territorial, cultural y social. Como sostiene Miguel Bartolomé (2010), en el marco histórico contemporáneo se han desarrollado procesos sociales de identificación relacionados con experiencias de participación política adquiridas en las organizaciones etnopolíticas que expresan la emergencia de nuevas identidades (reetnización).

Así, desde finales del siglo $\mathrm{XX}$ es patente un sostenido reposicionamiento etnopolítico, reforzado con una impensada visibilización como consecuencia de la expansión turística sobre su territorio. Esto ha provocado una nueva conflictividad en la disputa sobre el proceso reivindicatorio. La cuestión que se plantea es sobre el rol que va a desempeñar el turismo en contextos favorables de apertura social; si su papel será el de rescatar y dignificar lo étnico, y fortalecer estos reposicionamientos, o, por el contrario, reforzar y convalidar las relaciones de poder asimétricas consolidadas.

Bajo un esquema hegemónico del turismo, en cuanto al uso y el aprovechamiento económico del patrimonio y la cosmovisión mapuche, se niega su condición de otredad como sujeto social y cultural contemporáneo, que comparte los mismos factores de cambio y adaptación a las estructuras políticas y económicas. Para su promoción basada en el mercado, requiere de un poblador mapuche que haga referencia constantemente a una versión occidentalizada de un pasado idealizado, que se reinvente cada vez como pueblo originario. Todo esto, sin cuestionar las razones y las consecuencias de un genocidio y la posterior dispersión y aniquilamiento cultural que perduró y se acentuó durante todo el siglo XX. Un pasado que se hace presente en cada reivindicación étnica (Impemba, 2013).

Las formas convencionales y masificadas del turismo recortan y procesan la cuestión étnica de manera funcional al proceso de apropiación de la renta turística, poniendo en valor una tradición reinventada. "Si las identidades han sido forjadas con tradiciones inventadas y ficciones orientadoras sin respaldo histórico y cultural, solo se puede tener como resultado propuestas desarticuladas con los supuestos portadores de una determinada identidad étnica" (Barretto, 2005, p. 6).

En contextos especializados en el turismo, como lo es la región andino-patagónica abordada en este trabajo, se reproducen estereotipos y prejuicios. Estos se ponen de manifiesto en momentos de tensión ante los reposicionamientos étnicos e identitarios de base territorial de las comunidades mapuche. Estas últimas son presentadas a la opinión pública principalmente como asociadas a situaciones de conflictividad -toma de tierras, recuperación territorial, cortes de ruta-. Durante los últimos tres años del actual gobierno nacional, se han criminalizado los reclamos mapuche mediante la represión, la judicialización y la manipulación de los medios de comunicación nacionales y regionales. La exclusión de esta población como uno de los sectores marginados de la sociedad, que continúa en el actual siglo, y las prácticas estigmatizantes que conlleva, han obtenido como respuesta, sin embargo, la lucha de las pobla- 
ciones mapuche por el pleno reconocimiento de sus derechos.

En los espacios turísticos en la provincia del Neuquén conviven distintas realidades y frente a esa problemática se presentan, por lo menos, dos escenarios posibles: uno destinado a mostrar una imagen libre de problemas y que se muestra como un espacio preparado para satisfacer al visitante en un ambiente armónico con la naturaleza. La otra cara está conformada por un sector social invisibilizado y negado, perteneciente a la etnia mapuche, que pugna por la apropiación, la valorización y la gestión de su patrimonio en un espacio físico-social donde se concreten las manifestaciones simbólicas.

La producción del valor y la apropiación del patrimonio cultural como manifestaciones compartidas y vividas de una cultura se vinculan directamente a las especificidades del contexto socio-territorial del cual son símbolos característicos. Territorializar el patrimonio significa destacar que este es expresión de una comunidad particular, en el sentido que se encuentra siempre arraigado a un espacio propio, por lo cual se constituye en un patrimonio fuertemente territorializado.

Para el pueblo-nación mapuche el territorio no solo es entendido como un espacio en el cual transcurre la vida social, sino como un artífice de esa realidad, un territorio históricamente construido en el cual ocurren y se han desarrollado determinados procesos sociales y culturales que intervienen en la experiencia de vida de sus habitantes. Únicamente considerando estos distintos elementos se podrá comprender cuáles son los diversos sentidos a los que responde el proceso de activación social del patrimonio cultural.
Nos encontramos ahora ante un nuevo escenario de tensión frente a sectores que integran la superestructura turística y que pugnan por la explotación turística del paisaje desculturalizado. Los integrantes de este sector centran su interés en las consecuencias económicas de acciones como un corte de ruta o una toma de tierras en plena temporada. En contraparte, los otros invisibles (Impemba, 2013) implementan tales medidas como una forma de visibilización de sus necesidades y como factor de presión para ser escuchados y acceder de esta manera a los medios masivos de difusión y a la opinión pública.

La estigmatización del mapuche como sujeto social desconoce y niega las estrategias adaptativas de las sociedades subordinadas que les han resultado indispensables para sobrevivir en determinados contextos discriminatorios y racistas como el aquí desarrollado. El reposicionamiento etnopolítico antes mencionado en un entorno más favorable provocó la inclusión de la "cuestión mapuche" en la agenda política. Los conflictos que estallaron en San Martín de los Andes, Villa La Angostura o Villa Pehuenia no repercutieron tanto sobre las temporadas turísticas como en los esquemas de poder sobre los cuales se consolidaron las relaciones interétnicas a lo largo del siglo XX. Al mismo tiempo, con ellos quedó evidenciada la capacidad organizativa de las comunidades mapuche y el éxito obtenido por estas experiencias de lucha, que han sido replicadas por diversas comunidades indígenas del país y de Latinoamérica (Valverde, Maragliano, Impemba \& Trentini, 2011).

La reacción, a través de múltiples redes y pliegues, del poder político y económico en el contexto neuquino fue la elaboración de estrategias complejas tendientes a disminuir los enfrentamientos pero, al mismo tiempo, a 
neutralizar las situaciones de conflictividad. Las prácticas varían. Una de ellas es la cooptación de cuadros dirigenciales o pobladores con cierto liderazgo en sus comunidades por parte del partido político gobernante en la provincia del Neuquén desde hace más de sesenta años. Esta estrategia enlaza con la redacción y la firma de acuerdos entre las partes, varias veces reiterados y de difícil o nulo cumplimiento, con el fin de posponer y dilatar los procesos decisorios hasta finalizar cada temporada y renovar los reclamos al inicio de la siguiente.

También se han implementado compensaciones económicas por el uso de territorios de propiedad mapuche -como el caso del Cerro Chapelco- a modo de subconcesión con intermediación del Estado provincial. Esto va de la mano con las tácticas destinadas a captar parte de los integrantes de las comunidades mapuche, estableciéndoles pautas y condiciones para llevar a cabo actividades vinculadas al negocio turístico, con el consiguiente financiamiento discrecional a emprendimientos en sus territorios actuales o en proceso de reivindicación.

El turismo representa, por un lado, un factor que reproduce el inevitable choque de dos culturas y dos clases: dominante-subordinada. Una, que podría denominarse nosotros, es la que fija los criterios $y$, en definitiva, las reglas de juego a las cuales deben atenerse los otros, detentores de una identidad mapuche vinculada y acotada a la ruralidad. Como contrapartida, el turismo ha servido como herramienta para visibilizar y reposicionar a las diferentes comunidades mapuche ante el Estado y los intereses privados.

Los diversos centros turísticos del denominado Corredor de Los Lagos enfrentan, de esta manera, la contradicción de una estrategia de marketing que promueve la escenifi- cación de una vida pueblerina construida sobre una imagen de una naturaleza no modificada, en la cual el pueblo mapuche forma parte de sus atractivos turísticos, dentro de un paisaje aldeano libre de conflictos interétnicos y de clase. En forma simultánea, como contracara en este proceso dialéctico de incorporar la imagen de la etnia mapuche y sin proponérselo, el campo turístico le da existencia a quienes antes negaba, favoreciendo su reformulación pública como grupo, como personas físicas y sujetos sociales activos y contemporáneos.

El Cerro Chapelco y su centro de esquí, el más importante de la provincia del Neuquén y uno de los más reconocidos en Latinoamérica, el Cerro Belvedere y la cuenca del Lago Correntoso, con el acceso al centro de esquí Cerro Bayo en Villa La Angostura, el manejo y la titularidad sobre el entramado político de Pulmarí en Aluminé, o el cuestionamiento sobre la municipalización de Villa Pehuenia en territorios reivindicados como mapuche, son algunos ejemplos de cuestiones territoriales aún no resueltas. Estos espacios constituyen ámbitos propicios para analizar la disputa en un territorio donde la dimensión étnica adquiere significación y que cuenta con un complejo entramado del campo turístico con múltiples actores.

Una vez más se vuelven a actualizar las consecuencias del proceso histórico-social de constitución y localización de las comunidades mapuche pos Campaña del Desierto así como los efectos de las diversas prácticas políticas tanto nacionales (Parques Nacionales, Ejército, etc.) como provinciales (Partido Provincial hegemónico desde la mitad del siglo $X X$ ) en momentos en que sus acciones reivindicativas renuevan las estigmatizaciones del resto de la sociedad desde la perspectiva del turismo. 


\section{Notas}

${ }^{1}$ El 13 de mayo de 2019, la calificadora de riesgos MSCl anunció que Argentina volverá a posicionarse en la categoría de "mercado emergente" del MSCl Emerging Market. Recuperado en https:// www.perfil.com/noticias/economia/que-significa-argentina-vuelva-a-ser-mercado-emergente.phtml

${ }^{2}$ Región turística identificada como corredor en el sudoeste de la provincia del Neuquén. Abarca, entre otras localidades turísticas, a Villa Pehuenia, Aluminé, Junín de los Andes, San Martín de los Andes, Villa Traful y Villa La Angostura y los parques nacionales Lanín, Arrayanes y Nahuel Huapi.

${ }^{3}$ A fines del siglo XIX, durante el proceso de consolidación del Estado-nación argentino, se llevaron a cabo acciones militares contra la población mapuche con el objetivo de lograr su desplazamiento de las áreas de las cuencas de los ríos Negro y Neuquén, ubicados en el norte de la región patagónica. La importancia económica de estas campañas militares fue muy significativa dado que más de 60 millones de hectáreas pasaron a ser controladas por el gobierno de Buenos Aires. Desde 1876 hasta la finalización del siglo, distintas administraciones nacionales entregaron más de las dos terceras partes de las tierras enajenadas a un número muy reducido de personas. La incorporación de los territorios indígenas a la esfera de control estatal trajo como consecuencia inmediata la privatización y la concentración de importantes extensiones de tierra.

${ }^{4}$ La ocupación efectiva en la región andino-patagónica del sudoeste de la provincia del Neuquén se completó y reforzó con la radicación y el establecimiento de la Administración de Parques Nacionales

\section{Referencias bibliográficas}

APN (1997). Plan Preliminar de Manejo del Parque Nacional Lanín. Administración de Parques Nacionales.

Balazote, A. (2006). Winkas y mapuches: producción cultural y oferta turística en una aldea de montaña en Norpatagonia, Argentina. ILHA. Revista de Antropología, 8(1-2), 117-136. DOI: https://doi. org/10.5007/\%25x

Bartolomé, M. A. (2010). Interculturalidad y territorialidades confrontadas en América Latina. RUNA, XXXI(1), 9-29.

Barretto, M. (2005). Turismo étnico y tradiciones inventadas. En Santana Talavera, A. \& Prats, LI. (Coords.), El encuentro del turismo con el patrimonio cultural: concepciones teóricas y modelos de aplicación (pp. 39-56). Sevilla: Fundación el Monte, Federación de Asociaciones de Antropología del Estado Español, Asociación Andaluza de Antropología.

Bedoya, E. (2000). De la economía política a la ecología política: balance global del ecomarxismo y la crítica al desarrollo. En Viola, A. (Comp.), Antropología del desarrollo: teorías y estudios etnográficos en América Latina. Barcelona y Buenos Aires: Paidós.

Bonfil, G. (1995). Etnodesarrollo: sus premisas jurídicas, políticas
(APN) en la década de 1930. Las administraciones de los parques nacionales definieron, bajo el ideario conservacionista, su función geopolítica, una que completaba el proceso iniciado con la Campaña del Desierto en la medida que hizo efectiva la ocupación de zonas de frontera, facilitando el control militar de los límites internacionales y la dominación de los pobladores originarios.

${ }^{5}$ Permiso Precario de Ocupación y Pastaje. "Cuando el Parque Lanín fue creado en 1937, se otorgaron Permisos Precarios de Ocupación y Pastaje (P.P.O.P.) a los pobladores que quedaron incluidos dentro del área protegida, los que en el caso de pobladores criollos, ya estaban en la zona desde principios de 1900. El permiso era personal e intransferible y caducaba a la muerte del titular, pese a lo cual los descendientes de los titulares continuaron ocupando y utilizando las zonas autorizadas a sus antecesores. Estas dificultades hicieron que en 1991 la Administración de Parques Nacionales reconociera formalmente a estos asentamientos, admitiendo la permanencia de los pobladores que cumplían determinadas condiciones (20 años de residencia en el área, preexistencia de un PPOP, y otras)" (APN, 1997, p. 13).

${ }^{6}$ Neuquén Tur: oficina de gobierno local en Neuquén para la promoción turística.

${ }^{7}$ Se entiende por producto turístico el conjunto de recursos naturales, culturales y humanos con capacidad de atracción de visitantes que un área puede ofrecer, complementado por infraestructura y equipamiento de apoyo y promovido por una organización de venta.

y de organización. En Obras escogidas de Guillermo Bonfil Batalla, Tomo 2 (pp. 464-480). México: Instituto Nacional de Antropología e Historia, Instituto Nacional Indigenista.

Confederación Mapuce de Neuquén (2010). Propuesta para un KVME FELEN MAPUCE. Equipo Interdisciplinar e Intercultural del Proyecto. Gráfica Althabe, Newken, Puel Mapu.

Guerrero, R. M. (2005). Identidades territoriales y patrimonio cultural: la apropiación del patrimonio mundial en los espacios urbanos locales. F@ro (2), 289-306.

Impemba, M. (2005). La representación de la cultura mapuche en el discurso de los guías de turismo de San Martín de los Andes. (Tesis inédita de maestría en teorías y políticas de la recreación). Universidad Nacional del Comahue, Neuquén.

(2012). Relaciones interétnicas en la construcción de la identidad de San Martín de los Andes. (Tesis inédita de doctorado). Universidad de Buenos Aires, Buenos Aires.

(2013). ¿Los Otros invisibles? La cultura mapuche en el expansionismo turístico de San Martín de los Andes. Prólogo. En Valverde, S., Cultura mapuche y expansionismo turístico de San 
Martín de los Andes, Córdoba: Ferreyra.

Impemba, M. \& Maragliano, G. (2007). Conflictividad territorial y relaciones interétnicas en el expansionismo turístico en comunidades mapuche del sudoeste de la provincia del Neuquén, (pp. 147-170). En Rotman, M., Radovich, J. C. \& Balazote, A. (Eds.), Pueblos originarios y problemática artesanal: procesos productivos y de comercialización en agrupaciones Mapuche, Guaraní/Chané, Wichís, Qom/Tobas y Mocovíes. Córdoba: Universidad Nacional de Córdoba, Ferreyra.

Kropff, L. (2005). Activismo mapuche en Argentina: trayectoria histórica y nuevas propuestas. Simposio Antropología del Turismo, VI Congreso Argentino de Antropología Social. Consejo Latinoamericano de Ciencias Sociales, Mar del Plata.

Maragliano, G. (2010). Hotel Lacar: 100 años en la vida de San Martín de los Andes. Córdoba: Ferreyra.

NEUQUENTur (2016). Sitio oficial. Recuperado de http:// neuquentur.gob.ar/es/que-hacer/comunidades-mapuche/ (Consultado en junio de 2016).

Prats, LI. (1997). Antropología y patrimonio. Barcelona: Ariel. (2005). Concepto y gestión del patrimonio local. Cuadernos de Antropología Social (21), Cultura y patrimonio. Perspectivas contemporáneas en la investigación y la gestión, (pp. 17-35).

Radovich, J. C. \& Balazote, A. (2000). Mapuches en Neuquén: conflictos en el orden económico y simbólico (pp. 1-8). En Varios autores, El resignificado del desarrollo. Buenos Aires: UNIDA.

Trinchero, H. \& Balazote, A. (2007). De la economía política a la antropología económica. Buenos Aires: EUDEBA.

Valverde, S., Maragliano, G., Impemba, M. \& Trentini, F. (Coords.) (2011). Procesos históricos, transformaciones sociales y construcciones de fronteras: aproximaciones a las relaciones interétnicas. Estudios sobre Norpatagonia, Argentina y Labrador, Canadá. Buenos Aires: Universidad de Buenos Aires.

Valverde, S. \& Morey, E. (2005). Producción doméstica, mercado y actividad artesanal en comunidades mapuches del sur de la provincia de Neuquén. Cuadernos de Antropología Social (22), (95-114).

Vera, F. (1997). Análisis territorial del turismo: una nueva geografía del turismo. Barcelona: Ariel.

Williams, B. (1993). The Impact of de Precepts of Nationalism on the Concept of Culture: Making Grasshoppers of Naked Apes. Cultural Critique (24), 143-191. 